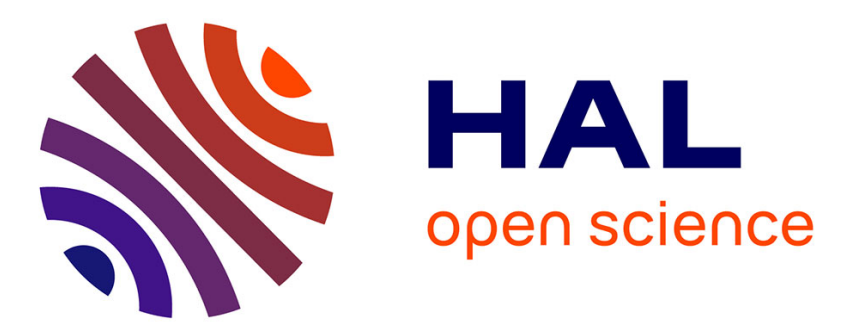

\title{
Combining acetabular and femoral morphology improves our understanding of the down syndrome hip.
}

\author{
Ziad Bakouny, Ayman Assi, Fares Yared, Nour Khalil, Elie Mansour, \\ Jean-Jacques Yaacoub, Wafa Skalli, Ismat Ghanem
}

\section{- To cite this version:}

Ziad Bakouny, Ayman Assi, Fares Yared, Nour Khalil, Elie Mansour, et al.. Combining acetabular and femoral morphology improves our understanding of the down syndrome hip.. Clinical Biomechanics, 2018, 58, pp.96-102. 10.1016/j.clinbiomech.2018.07.016 . hal-02500543

\section{HAL Id: hal-02500543 \\ https://hal.science/hal-02500543}

Submitted on 6 Mar 2020

HAL is a multi-disciplinary open access archive for the deposit and dissemination of scientific research documents, whether they are published or not. The documents may come from teaching and research institutions in France or abroad, or from public or private research centers.
L'archive ouverte pluridisciplinaire HAL, est destinée au dépôt et à la diffusion de documents scientifiques de niveau recherche, publiés ou non, émanant des établissements d'enseignement et de recherche français ou étrangers, des laboratoires publics ou privés. 


\title{
Combining acetabular and femoral morphology improves our understanding of the down syndrome hip
}

\author{
Ziad Bakouny ${ }^{\mathrm{a}}$, Ayman Assi ${ }^{\mathrm{a}, \mathrm{b}, *}$, Fares Yared $^{\mathrm{a}}$, Nour Khalil ${ }^{\mathrm{a}}$, Elie Mansour ${ }^{\mathrm{a}}$, \\ Jean Jacques Yaacoub ${ }^{\mathrm{a}}$, Wafa Skalli ${ }^{\mathrm{b}}$, Ismat Ghanem ${ }^{\mathrm{a}, \mathrm{c}}$ \\ ${ }^{a}$ Laboratory of Biomechanics and Medical Imaging, Faculty of Medicine, University of Saint-Joseph, Beirut, Lebanon \\ ${ }^{\mathrm{b}}$ Institut de Biomécanique Humaine Georges Charpak, Arts et Métiers ParisTech, Paris, France \\ ${ }^{\mathrm{c}}$ Hôtel-Dieu de France Hospital, University of Saint-Joseph, Beirut, Lebanon
}

Keywords:

Down syndrome

Hip

Three-dimensional

Hip instability

Standing position

\section{A B S T R A C T}

Background: Hip instability is frequent in patients with Down syndrome. Recent studies have suggested that skeletal hip alterations are responsible for this instability; however, there are currently no studies simultaneously assessing femoral and acetabular anatomy in subjects with Down syndrome in the standing position. The aim was to analyze the three-dimensional anatomy of the Down syndrome hip in standing position.

Methods: Down syndrome subjects were age and sex-matched to asymptomatic controls. All subjects underwent full body biplanar X-rays with three-dimensional reconstructions of their pelvises and lower limbs. Parameter means and distributions were compared between the two groups.

Findings: Forty-one Down syndrome and 41 control subjects were recruited. Acetabular abduction (mean $=52^{\circ}$ $\left[\mathrm{SD}=9^{\circ}\right]$ vs. mean $\left.=56^{\circ}\left[\mathrm{SD}=8^{\circ}\right]\right)$ and anteversion (mean $=14^{\circ}\left[\mathrm{SD}=8^{\circ}\right]$ vs. mean $\left.=17.5^{\circ}\left[\mathrm{SD}=5^{\circ}\right]\right)$ as well as posterior acetabular sector angle (mean $=91^{\circ}\left[\mathrm{SD}=7^{\circ}\right]$ vs. mean $=94^{\circ}\left[\mathrm{SD}=7^{\circ}\right]$ ) were significantly lower in Down syndrome subjects compared to controls $(\mathrm{P}<0.01)$. Anterior acetabular sector angle (mean $=62^{\circ}\left[\mathrm{SD}=10^{\circ}\right]$ vs. mean $\left.=59^{\circ}\left[\mathrm{SD}=7^{\circ}\right] ; \mathrm{P}<0.01\right)$ was significantly higher in Down syndrome compared to controls. The distributions of acetabular anteversion $(\mathrm{P}=0.002 ; \mathrm{V}=0.325)$, femoral anteversion $(\mathrm{P}=0.004 ; \mathrm{V}=0.309)$ and the instability index $(\mathrm{P}<0.001 ; \mathrm{V}=0.383)$ were significantly different between the two groups, with subjects with Down syndrome having both increased anteversion and retroversion for each of these parameters.

Interpretation: Subjects with Down syndrome were found to have a significantly altered and more heterogeneous anatomy of their proximal hips compared to controls. This heterogeneity suggests that treatment strategies of hip instability in Down syndrome should be subject-specific and should rely on the understanding of the underlying three-dimensional anatomy of each patient.

\section{Introduction}

Down syndrome (DS), or trisomy 21 , is the most frequent chromosomal abnormality with an incidence of 1/660 live births (Mik et al., 2008). Hip instability is one of the most commonly occurring (1.3 to 7\%) orthopedic problems (Aprin et al., 1985; Assi et al., 2018; Bennet et al., 1982; Diamond et al., 1981; Mansour et al., 2017; Shaw and Beals, 1992) in these subjects. It is a significant source of morbidity during both childhood and adulthood (Bennet et al., 1982; Diamond et al., 1981), and is especially challenging to treat (Boylan et al., 2015; Kelley and Wedge, 2013; Knight et al., 2011; Sankar et al., 2011).
While hip pathologies in non-DS subjects mostly produce anterior instability, posterior hip subluxation and dislocation have been shown to be more frequent in subjects with DS (Bennet et al., 1982; Sankar et al., 2011). Hip instability in subjects with DS has long been believed to be related to hypotonia and ligamentous laxity (Bennet et al., 1982; Hresko et al., 1993); however, recent studies based on CT scans or Xrays, in the supine position, have suggested that either acetabular retroversion or increased neck shaft angle could be responsible for the observed posterior instability, and treatment strategies have been accordingly suggested (Kelley and Wedge, 2013; Knight et al., 2011; Sankar et al., 2011). However, acetabular alignment has been 
previously shown to be dependent upon body positioning during imaging (Babisch et al., 2008) and studies on other populations have underlined the importance of concomitantly assessing femoral and acetabular anatomy in order to assess hip anatomy (Dorr et al., 2009; Tönnis and Heinecke, 1999). There are currently no studies simultaneously assessing femoral and acetabular anatomy in subjects with Down syndrome in the standing position. The aim of this study was to analyze the three-dimensional anatomy of the Down syndrome hip in the standing position.

\section{Methods}

\subsection{Study design}

This is a cross-sectional, Level III, IRB approved descriptive study of acetabular and lower limb anatomy in subjects with Down syndrome (DS). The inclusion criterion was the clinical diagnosis of Down syndrome. The exclusion criterion was previous musculoskeletal surgeries to the pelvis, spine or lower limbs.

Subjects with Down syndrome were recruited from a center which provides work opportunities and schooling for persons with special needs and had not been specifically referred for hip-related complaints. Subjects were sex and age-matched to a control group of asymptomatic subjects. Control subjects were excluded if they had any musculoskeletal disease or if they presented any pain at the time of the study. All subjects (and their legal guardians, in the case of persons with DS) signed a written informed consent form.

\subsection{Data acquisition}

The following demographic characteristics were noted for each subject: sex, age, weight, height, and body mass index (BMI). Each subject then underwent a full body biplanar X-ray exam (EOS Imaging, Paris, France). All subjects were asked to stand in the free standing position during X-ray acquisition (Horton et al., 2005; Janssen et al., 2009).

Their pelvises and lower limbs were reconstructed in 3D by an operator (an orthopedic resident who had been previously trained on a separate set of radiographs to perform the reconstructions) using a specifically designed software (Arts et Métiers ParisTech, Paris, France) and SterEOS ${ }^{\circledR}$ (EOS Imaging, Paris, France), respectively.

The reconstruction techniques of both the pelvis (Ghostine et al., 2016) and the lower limbs (Assi et al., 2013; Quijano et al., 2013) have been previously validated. Briefly, for both the pelvis and the lower limbs, the reconstruction technique is as follows: an operator identifies anatomical bony landmarks on both the antero-posterior and lateral radiographs. This allows a primary estimation of the three-dimensional skeletal segment (pelvis or lower limb) shape. The model is then retroprojected on to the antero-posterior and lateral radiographs to be manually adjusted by the operator as best fit between the radiographic contours and the retro-projected model. The dedicated software was subsequently used to automatically measure the parameters in 3D based on the reconstructions.

The following, previously defined, parameters were generated from these 3D reconstructions: Anterior Pelvic Plane Angle (APPA) (Rousseau et al., 2009), Pelvic tilt (PT) (Vialle et al., 2005), Pelvic Incidence (PI) (Vialle et al., 2005), Vertical Center Edge Angle (VCE) (Ghostine et al., 2016), percentage of coverage of the femoral head by the acetabulum (\%FHC) (Ghostine et al., 2016), Acetabular Abduction (AAb) (Ghostine et al., 2016), Acetabular Anteversion (AAnt) (Ghostine et al., 2016), Anterior Acetabular Sector Angle (AASA) (Ghostine et al., 2016), Posterior Acetabular Sector Angle (PASA) (Ghostine et al., 2016), Femoral Anteversion (FA) (Gaumétou et al., 2014), Neck-Shaft Angle (Bendaya et al., 2015) (NSA), Knee Valgus Angle (KVA) and Tibial Torsion (TT) (Gaumétou et al., 2014). These parameters are represented in Figs. 1 and 2.
The validity (compared to three-dimensional computed tomography reconstructions) and reliability of most of the pelvic parameters reported in the current study had been previously assessed by Ghostine et al. (Ghostine et al., 2016): among the included parameters, the absolute bias $(\delta)$ ranged between $0.1^{\circ}$ for PI or PT and $2.9^{\circ}$ for PASA and the reproducibility $\left(\mathrm{S}_{\mathrm{R}}\right)$ ranged between $0.8^{\circ}$ for PT and $3.4^{\circ}$ for PASA.

The reliability of the lower limb parameters had been previously evaluated in typically developing and cerebral palsy children by Assi et al. (Assi et al., 2013): the values of the reliability assessment in the typically developing children ranged between $0.4^{\circ}$ for KVA and $3.0^{\circ}$ for TT.

Since subject positioning (and particularly pelvic tilt) is known to significantly influence acetabular parameters (Lazennec et al., 2011; Lembeck et al., 2005), acetabular abduction and anteversion as well as the anterior and posterior acetabular sector angles were all computed in relation to the anterior pelvic plane (Babisch et al., 2008). The instability index was additionally calculated as the arithmetic sum of femoral anteversion and acetabular anteversion, as previously defined by Tonnis and Heinecke (Tönnis and Heinecke, 1999).

It should be noted that two different parameters measured the tilt of the pelvis in the sagittal plane in this study: the anterior pelvic plane angle (APPA) which measures the pelvic tilt in relation the anterior pelvic plane crossing the anterior superior iliac spines and the symphysis pubis (increases with pelvic anteversion) and the pelvic tilt (PT) which measures the displacement in the sagittal plane of the middle of the sacral plate in relation to the middle of the bicoxofemoral axis (increases with pelvic retroversion). Both definitions were included since APPA is typically used by orthopedic hip surgeons while PT is more frequently used by spine surgeons.

In addition the theoretical pelvic tilt was computed for each subject as described by Vialle et al. (Vialle et al., 2005) as theoretical $\mathrm{PT}=-7+0.37 * \mathrm{PI}$. In order to quantify the difference between the PT of each subject and his theoretical PT the delta PT was computed as the arithmetic difference between the true PT and the theoretical PT.

\subsection{Statistical analysis}

All variables were tested for normality using the Shapiro-Wilk test and for equality of variance using Levene's test.

The demographic characteristics as well as the pelvic and lower limb parameters were compared between the two groups using either Student's, Mann-Whitney's or Welch's unequal variance tests depending on the normality and equality of variance of each parameter.

Previously defined clinically relevant thresholds (Table 1), when available, were derived from the literature in order to classify the hips of the subjects in both groups for each of the following parameters: vertical center edge angle (Tannast et al., 2015), neck shaft angle (Tönnis, 1984), acetabular anteversion, femoral anteversion and instability index (Tönnis and Heinecke, 1999).

In order to compare the distributions of each of these parameters according to their respective classifications between the Down syndrome and control groups, the Chi-squared test was computed between the distributions of the two groups. The effect sizes of significant differences were quantified using Cramer's V. In order to examine whether acetabular and femoral anteversions or acetabular abduction and neck shaft angle are related, Spearman correlations were conducted between these pairs of parameters in each group separately. Furthermore, in order to evaluate the effect of age on the acetabular and femoral parameters in each group, Spearman correlations were computed between age and these parameters.

The significance level was set at 0.05 . Statistical analysis was performed using IBM SPSS Statistics v.20.0 (IBM Corporation, New York, USA) and Xlstat version 2016.05.3 (Addinsoft, Paris, France). 


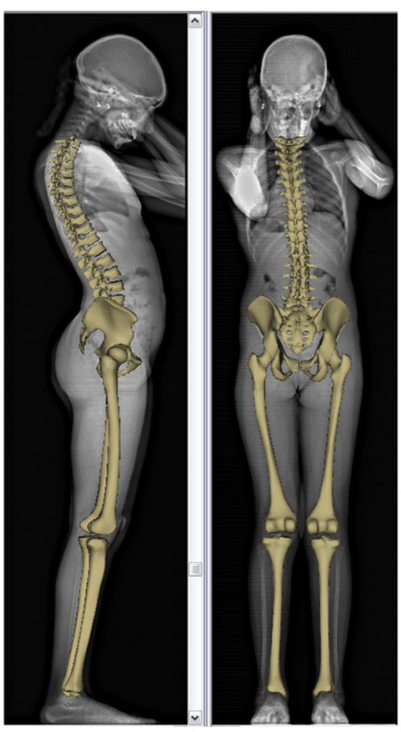

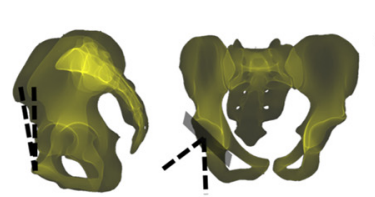

b

a
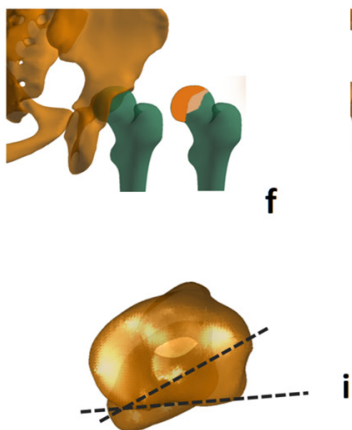

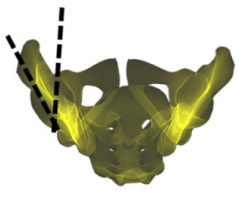

C

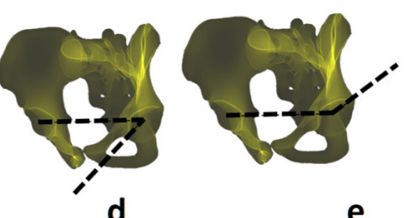

d

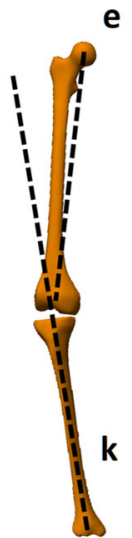

Fig. 1. Pelvic, acetabular and lower limb parameters calculated from pelvic 3D reconstructions: a) Anterior pelvic plane angle b) Acetabular abduction c) Acetabular anteversion d) Anterior acetabular sector angle e) Posterior acetabular sector angle f) Percentage of coverage of the femoral head by the acetabulum g) Vertical center edge angle h) Femoral anteversion (FA) i) Tibial torsion j) Neck-shaft angle k) Knee valgus angle.

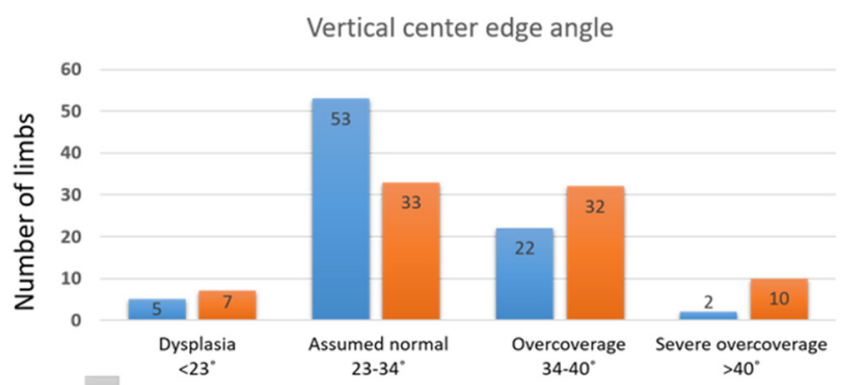

a

Acetabular anteversion

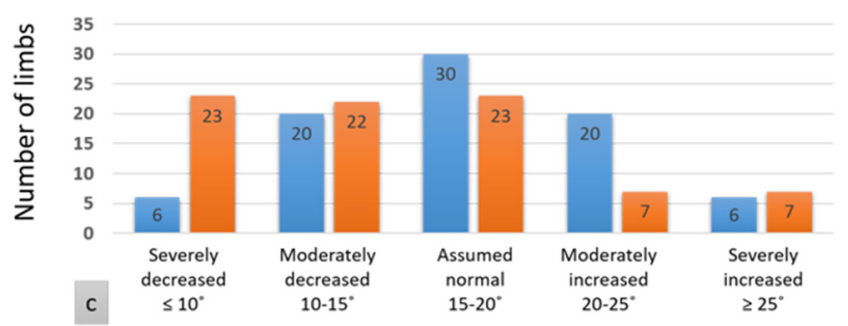

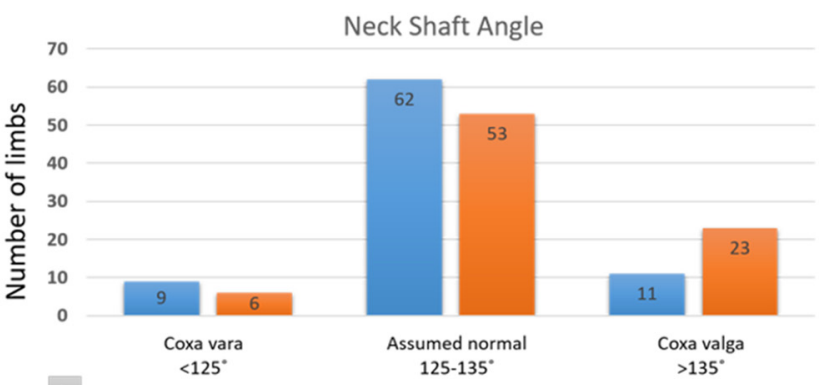

b
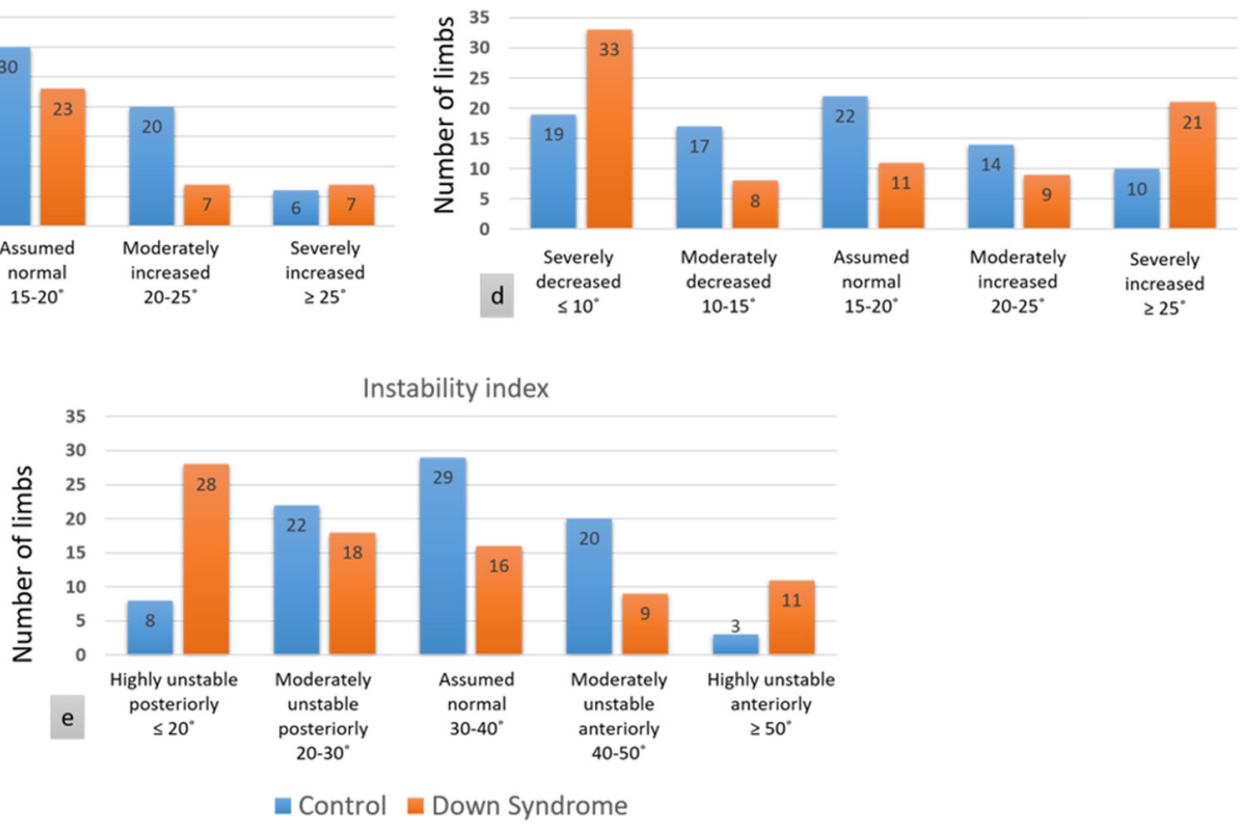

Fig. 2. Distribution of Down syndrome and control subjects' hips for (a) vertical center edge angle, (b) neck shaft angle, (c) anatomical acetabular anteversion, (d) femoral anteversion and (e) anatomical instability index. 
Table 1

Thresholds for the classifications of vertical center edge angle, neck shaft angle, acetabular anteversion, femoral anteversion and instability index.

\begin{tabular}{|c|c|c|c|c|c|}
\hline Angle & Vertical center edge angle & Neck shaft angle & Acetabular anteversion & Femoral anteversion & Instability index \\
\hline Reference & Tannast et al., 2015 & Tönnis, 1984 & Tönnis and Heinecke, 1999 & & Tönnis and Heinecke, 1999 \\
\hline \multirow[t]{10}{*}{ Thresholds } & $\begin{array}{l}\text { Dyplasia } \\
<23^{\circ}\end{array}$ & $\begin{array}{l}\text { Coxa vara } \\
<125^{\circ}\end{array}$ & $\begin{array}{l}\text { Severely decreased } \\
<10^{\circ}\end{array}$ & & Highly unstable posteriorly \\
\hline & & $<125^{\circ}$ & $\leq 10^{\circ}$ & & $\leq 20^{\circ}$ \\
\hline & Assumed normal & Assumed normal & Moderately decreased & & Moderately unstable posteriorly \\
\hline & $23-34^{\circ}$ & $125-135^{\circ}$ & $10-15^{\circ}$ & & $20-30^{\circ}$ \\
\hline & Overcoverage & Coxa valga & Assumed normal & & Assumed normal \\
\hline & $34-40^{\circ}$ & $>135^{\circ}$ & $15-20^{\circ}$ & & $30-40^{\circ}$ \\
\hline & Severe overcoverage & & Moderately increased & & Moderately unstable anteriorly \\
\hline & $>40^{\circ}$ & & $20-25^{\circ}$ & & $40-50^{\circ}$ \\
\hline & & & Severely increased & & Highly unstable anteriorly \\
\hline & & & $\geq 25^{\circ}$ & & $\geq 50^{\circ}$ \\
\hline
\end{tabular}

\section{Results}

\subsection{Subject demographics}

Forty-one subjects (13 females, 28 males; mean age $=17.5$ years) with DS were enrolled in this study. These subjects were age and sexmatched to 41 asymptomatic subjects (13 females, 28 males; mean age $=17.8$ years). The demographics of the sample, along with between-group comparisons, were reported in Table 2. Control subjects were significantly heavier and taller compared to subjects with DS but both groups of subjects had similar BMI and age.

\subsection{Differences in pelvic, acetabular and lower limb alignment}

The acetabular and lower limb alignment parameters of subjects with DS and control subjects are compared in Table 3. Subjects with DS were found to have a significantly more anteverted pelvis compared to control subjects (anterior pelvic plane angle significantly higher and pelvic tilt significantly lower compared to control subjects; P $<0.01$ ). Furthermore, the delta PT was significantly lower in the DS group compared to the control group $(\mathrm{P}<0.01)$.

Subjects with DS had significantly greater lateral coverage of the femoral head by the acetabulum $(P=0.03)$. Acetabular abduction, acetabular anteversion and posterior acetabular sector angle were all found to be significantly decreased in subjects with Down Syndrome compared to control subjects $(\mathrm{P}<0.01$ ), whereas the anterior acetabular sector angle was found to be significantly larger in subjects with Down syndrome compared to control subjects $(P<0.01)$. The instability index tended to be lower in subjects with Down syndrome compared to control subjects, although the difference did not reach the threshold of statistical significance $(P=0.08)$.

As for lower limb alignment, neck shaft angle was significantly more elevated in Down syndrome compared to control subjects $(\mathrm{P}=0.01)$.

Table 2

Demographic characteristics of the Down syndrome and control groups with between-group comparisons.

\begin{tabular}{llll}
\hline & $\begin{array}{l}\text { Down } \\
\text { syndrome }\end{array}$ & Control & $\begin{array}{l}\text { Between-group comparisons } \\
\text { (P-value) }\end{array}$ \\
\hline $\begin{array}{llll}\text { Number of } \\
\text { subjects }\end{array}$ & 41 & 41 & \\
Age (years) & $17.5(6.2)$ & $17.8(5.5)$ & 0.18 \\
Sex & $13 \mathrm{~F} / 28 \mathrm{M}$ & $13 \mathrm{~F} / 28 \mathrm{M}$ & 1.00 \\
Height $(\mathrm{m})$ & $1.45(0.09)$ & $1.65(0.18)$ & $<\mathbf{0 . 0 1}$ \\
Weight $(\mathrm{kg})$ & $52.9(14.6)$ & $66.5(21.0)$ & $<\mathbf{0 . 0 1}$ \\
BMI $\left(\mathrm{kg} / \mathrm{m}^{2}\right)$ & $24.8(6.5)$ & $23.6(3.6)$ & 0.15 \\
\hline
\end{tabular}

F: females / M: Males.

All values are reported as: mean (SD).

Bold values represent statistically significant differences.

* Significant at the $<0.05$ level.
Table 3

Differences in acetabular and lower limb alignment between the Down Syndrome and control groups.

\begin{tabular}{|c|c|c|c|}
\hline & $\begin{array}{l}\text { Down } \\
\text { syndrome } \\
(\mathrm{N}=41)\end{array}$ & $\begin{array}{l}\text { Control } \\
(\mathrm{N}=41)\end{array}$ & $\begin{array}{l}\text { Between-group } \\
\text { comparisons } \\
\text { (P-value) }\end{array}$ \\
\hline \multicolumn{4}{|l|}{ Pelvic and acetabular alignment } \\
\hline Anterior pelvic plane angle $\left(^{\circ}\right)$ & $1.3(9.4)$ & $-3.6(4.9)$ & $<0.01 *$ \\
\hline Pelvic incidence $\left({ }^{\circ}\right)$ & $53.2(13.1)$ & $45.1(10.2)$ & $<0.01$ \\
\hline Pelvic tilt $\left({ }^{\circ}\right)$ & $4.9(9.1)$ & $8.1(6.4)$ & $<0.01$ \\
\hline Theoretical pelvic tilt $\left({ }^{\circ}\right)$ & $12.7(4.8)$ & $9.7(3.8)$ & $<0.01 *$ \\
\hline Delta pelvic tilt $\left({ }^{\circ}\right)$ & $-7.8(6.5)$ & $-1.5(4.0)$ & $<0.01 *$ \\
\hline Vertical center edge angle $\left({ }^{\circ}\right)$ & $33.2(6.7)$ & $31.1(5.2)$ & 0.03 \\
\hline $\begin{array}{l}\text { Anatomical acetabular } \\
\text { abduction }\left({ }^{\circ}\right)^{\mathrm{a}}\end{array}$ & $52.2(8.8)$ & $56.2(7.7)$ & $<0.01$ \\
\hline $\begin{array}{c}\text { Anatomical acetabular } \\
\text { anteversion }\left({ }^{\circ}\right)^{\mathrm{a}}\end{array}$ & $14.1(7.7)$ & $17.4(5.2)$ & $<0.01$ \\
\hline $\begin{array}{l}\text { Anatomical anterior } \\
\text { acetabular sector angle } \\
\left({ }^{\circ}\right)^{\mathrm{a}}\end{array}$ & $62.4(10.0)$ & $59.4(7.2)$ & $<0.01 *$ \\
\hline $\begin{array}{l}\text { Anatomical posterior } \\
\text { acetabular sector angle } \\
\left({ }^{\circ}\right)^{\mathrm{a}}\end{array}$ & $91.2(7.6)$ & $94.1(7.0)$ & $0.01 *$ \\
\hline Instability index $\left({ }^{\circ}\right)^{\mathrm{a}}$ & $29.2(17.4)$ & $33.1(9.8)$ & 0.08 \\
\hline $\begin{array}{l}\text { Percentage of femoral head } \\
\text { coverage by the } \\
\text { acetabulum (\%) }\end{array}$ & $43.4(4.7)$ & $44.2(3.3)$ & 0.13 \\
\hline \multicolumn{4}{|l|}{ Lower limb alignment } \\
\hline Femoral anteversion $\left({ }^{\circ}\right)$ & $15.0(13.9)$ & $15.6(9.9)$ & 0.74 \\
\hline Neck shaft angle $\left(^{\circ}\right)$ & $132.7(5.8)$ & $130.7(4.8)$ & $0.01 *$ \\
\hline Knee valgus angle $\left({ }^{\circ}\right)$ & $0.5(3.1)$ & $-0.2(2.4)$ & 0.13 \\
\hline Tibial torsion $\left({ }^{\circ}\right)$ & $26.9(7.0)$ & $28.3(7.5)$ & 0.16 \\
\hline
\end{tabular}

All values are reported as: mean (SD).

Bold values represent statistically significant differences.

a Anatomical acetabular parameters are calculated in relation to the anterior pelvic plane.

* Significant at the $<0.05$ level.

\subsection{Acetabular and lower limb parameter distributions in Down syndrome and control subjects}

The distributions of femoral and acetabular parameters of both control and Down syndrome subjects according to previously described classifications were presented in Fig. 2. None of the five parameters in Fig. 2 were found to be significantly non-normally distributed when tested in each of the two groups ( $P>0.05)$.

The distribution of the vertical center edge angle $(P=0.007$; $\mathrm{V}=0.272$ ) was found to significantly differ between the Down syndrome and control groups. In fact, more Down syndrome hips tended to be more overcovered or severely overcovered and less within the assumed normal range compared to control hips.

The difference in the distributions of the neck shaft angle between the DS and control hips did not reach the threshold of statistical significance ( $\mathrm{P}=0.063$; Fig. 2 ) but subjects with Down syndrome tended 
to be shifted towards coxa valga compared to control subjects.

The distributions of acetabular anteversion ( $\mathrm{P}=0.002 ; \mathrm{V}=0.325)$, femoral anteversion ( $P=0.004 ; \mathrm{V}=0.309)$ and the instability index ( $\mathrm{P}<0.001 ; \mathrm{V}=0.383$ ) were found to significantly differ between the Down syndrome and control groups (Fig. 2).

The hips of subjects with Down syndrome tended to be shifted towards decreased acetabular anteversion and to be more frequently classified as both having increased and decreased femoral anteversion, with less hips around the assumed normal range for both femoral and acetabular anteversion compared to control subjects.

This was also true for the instability index, for which DS hips were found to be more frequently either highly unstable anteriorly or posteriorly, with fewer hips around the assumed normal range compared to control hips.

Furthermore, acetabular abduction and neck shaft angle were not found to be significantly correlated in either the control or DS groups $(\mathrm{P}>0.05)$. However, femoral and acetabular anteversions were found to be significantly negatively correlated in the control $(\mathrm{P}=0.049$; $r=-0.218$ ) but not the DS group ( $\mathrm{P}=0.093)$. Age was only found to be significantly negatively correlated to the NSA in the control group $(\mathrm{P}=0.043 ; r=-0.224)$ and to the instability index in the DS group $(\mathrm{P}=0.016 ; r=-0.267)$.

\section{Discussion}

This is the first study to compare three-dimensional hip parameters, in the standing position, between 41 subjects with Down syndrome and 41 age and sex-matched asymptomatic subjects. Subjects with DS were found to have significantly altered and more heterogeneous proximal femur anatomy and acetabular alignment compared to control subjects.

Acetabular alignment has been previously shown to be influenced by subjects' age (in particular before skeletal maturity) (Hingsammer et al., 2015) and sex (Zeng et al., 2012). In this study, Down syndrome and control subjects were matched for age and sex in order to avoid such biases in comparisons between the two groups. Furthermore, while control subjects had significantly more elevated height and weight compared to subjects with Down syndrome, both groups were found to have similar BMI (Table 2).

Subjects with Down syndrome were found to have increased lateral coverage (increased VCE angle) of the femoral head by the acetabulum compared to control subjects (Table 3). This finding is somewhat in contrast to those of previous studies on subjects with Down syndrome, which had reported that these subjects tend to have dysplastic hips, with decreased lateral coverage of the femoral head by the acetabulum (Bennet et al., 1982; Kelley and Wedge, 2013; Sankar et al., 2011). The discrepancy in results could be explained by the differences in patient populations. While previous studies had mostly reported on subjects with Down syndrome who had been specifically referred for management of hip subluxation or dislocation (Bennet et al., 1982; Kelley and Wedge, 2013; Knight et al., 2011; Sankar et al., 2011), the subjects in this study had not been specifically referred for hip-related complaints. Furthermore, although the mean vertical center edge angle only slightly deferred in subjects with DS compared to controls, these patients were found to have significantly more heterogeneous lateral coverage (Fig. 2a). In particular, 10 (12\%) DS hips were classified as severely overcovered compared to just 2 (2\%) control hips. This increased prevalence of overcovered hips in Down syndrome subjects could partly explain the previously reported increased incidence of osteoarthritis in non-dysplastic DS hips (Zywiel et al., 2013).

Furthermore, subjects with DS were found to have a moderately increased neck shaft angle compared to control subjects $\left(132.7^{\circ}\right.$ vs. $130.7^{\circ}$ ). Some previous studies have suggested that the neck shaft angle is much larger in Down syndrome subjects $\left(167^{\circ}\right)$ and have consequently recommended femoral varus osteotomy as treatment for hip instability in this population (Knight et al., 2011). However, other studies had, similarly to the findings of the current study, found that
Down syndrome subjects tend to have only very moderate increases in neck shaft angle $\left(134^{\circ}\right.$ ) (Shaw and Beals, 1992). Such differences between previous studies have been suggested to be partly due to the difficulty in standardizing these patients' positioning during X-ray acquisition (Kelley and Wedge, 2013), especially in the presence of hip rotation. In this study, the use of biplanar X-rays with three-dimensional reconstruction for the assessment of hip anatomy, which has been previously shown to decrease the effect of patient positioning bias (Melhem et al., 2016), should have allowed precise evaluation of the anatomy of the Down syndrome hip.

Femoral anteversion had been reported to be significantly more elevated in subjects with Down syndrome, and its correction by femoral derotational osteotomy (Knight et al., 2011) had been previously proposed as a treatment for hip instability in this population. In this study, subjects with DS were found to have similar mean anteversion compared to control subjects (15.0 vs. $15.6^{\circ}$, respectively; Table 3 ). However, when the distribution of femoral anteversion was compared between the two groups, DS hips were significantly more frequently classified as having both severely increased and decreased femoral anteversion compared to control subjects. In fact, 33 (40\%) of DS hips had femoral anteversion of $<10^{\circ}$ and $21(26 \%)$ of $>25^{\circ}$. Therefore, while previous studies had reported increased femoral anteversion in subjects with DS (Kelley and Wedge, 2013; Knight et al., 2011; Sankar et al., 2011), the results of this study suggest that even severely decreased femoral anteversion is frequent in subjects with DS.

The pelvis of subjects with DS was found to be significantly more anteverted compared to control subjects (increased APPA and decreased PT). In order to investigate whether this difference was due to differences in pelvic bony anatomy (i.e. pelvic incidence) or due to a positional anteversion, the theoretical PT and the delta PT (arithmetic difference between true PT and theoretical PT) were computed for all subjects. Subjects with DS were found to have a significantly lower (more negative) delta PT compared to asymptomatic subjects, indicating that the difference between their true PT and their theoretical PT (the theoretical PT calculated from their pelvic incidence) was significantly larger than the difference between the true PT and theoretical PT of control subjects. This result therefore indicated that the increased pelvic anteversion of subjects with DS is in fact not accounted for by the difference in PI between the two populations.

Since the pelvis was found to be significantly more anteverted in subjects with DS compared to controls and since pelvic tilt has been previously shown to affect the assessment of acetabular alignment (Babisch et al., 2008), acetabular alignment parameters, calculated in relation to the anterior pelvic plane, were computed. While the standing position and the adjustment for pelvic tilt in acetabular parameter measurement are not routinely used in clinical practice, they allow the evaluation of acetabular anatomy without the bias induced by positioning. These parameters would also remain accurate in an operative setting since the surgeon could either use a navigation system (similar to the one used in total hip arthroplasty placement)(Babisch et al., 2008; Kumar et al., 2012) or position the patient such as it is at $0^{\circ}$ of tilt (APPA $=0^{\circ}$ ) in order to remain concordant with the measurements performed by this system.

Acetabular anteversion was found to be significantly smaller in subjects with DS, which is in accordance with previous studies on this patient population (Abousamra et al., 2016; Sankar et al., 2011; Sankar et al., 2012; Woolf and Gross, 2003). Furthermore, associated anterior and posterior sector angles, which reflect anterior and posterior coverage of the femoral head by the acetabulum, were accordingly increased and decreased, respectively. Despite these differences, the percentage of three-dimensional coverage of the femoral head by the acetabulum was found to be similar between both groups. Therefore, subjects with DS seem to have similar overall coverage of the femoral head by the acetabulum, with the decrease in posterior coverage compensated by an increase in anterior coverage.

When the distribution of acetabular anteversion was compared 
between Down syndrome and control subjects, 23 (28\%) DS hips compared to only $6(7 \%)$ control hips were found to be severely retroverted. Interestingly, a similar number of Down syndrome hips were found to have severely increased acetabular anteversion compared to controls (7\% vs. $9 \%$, respectively; Fig. 2c). Therefore, although mean anatomical acetabular anteversion was only slightly decreased in DS hips compared to controls, the anatomy of DS hips was found to be significantly more heterogeneous with a large proportion of hips presenting with severe retroversion.

Furthermore, in order to investigate whether changes in the femoral component were compensated for by changes in the acetabular component, correlations between these components in the frontal and axial planes were computed. While acetabular abduction and NSA were not found to be significantly correlated in either group, femoral anteversion was found to be significantly negatively correlated to acetabular anteversion in only the control but not the DS group. This result suggests that anatomical changes in the acetabular or femoral components in the axial plane seem to be somewhat compensated for by the other component in the control group but not in the DS group.

The instability index, which was proposed by Tonnis and Heinecke (Tönnis and Heinecke, 1999), is a measure of the anatomical predisposition of hips to instability, with a large value predisposing to anterior instability and a small value to posterior instability. Although, mean instability index was similar between the two groups (Table 3), a significantly larger proportion of Down syndrome hips were found to be morphologically predisposed to instability. In particular, posterior anatomical instability was significantly more prevalent in Down syndrome compared to control subjects ( $34 \%$ vs. $10 \%$; Fig. 2 e), which was in accordance with the finding of posterior acetabular wall deficiency of previous studies (Abousamra et al., 2016; Sankar et al., 2011; Sankar et al., 2012; Woolf and Gross, 2003). However, the prevalence of DS hips which are highly predisposed to anterior instability was also significantly larger compared to controls ( $13 \%$ vs. $4 \%$; Fig. 2e). This anterior instability has not been previously reported in the literature and may only be an anatomical predisposition that does not manifest clinically in subjects with DS. However, it is also possible that only posterior instability had been previously reported in the literature since it is considered to be atypical compared to the usual anterior instability which is encountered in more common pathologies such as developmental dysplasia of the hip. Therefore, our findings support the hypothesis of a morphological predisposition to posterior instability of the DS hip, which is caused by anomalies of both the femur and acetabulum. However, a non-negligible proportion of DS hips seems to be anatomically predisposed to anterior instability and should, therefore, be managed accordingly.

A limitation of this study is its small sample size. It has been suggested that the anatomical anomalies of the DS hip progress throughout childhood, from an initial phase of Ortolani-positive hips to a fixed dislocation phase (Bennet et al., 1982), and even in adulthood (Hresko et al., 1993). A larger sample size with a large age range would have allowed the comparison of three-dimensional anatomical hip anomalies between different age groups in order to understand the effect of age on the anatomy of the hip in this patient population. However, in this sample age was only found to be weakly correlated to NSA in the control group and to the instability index in the DS group. While these results are limited by the relatively small sample size, age did not seem to be strongly related to the femoral and acetabular parameters evaluated in this study in either DS or control subjects. Another limitation of this study is that it evaluated the bony hip morphology in subjects with Down syndrome who had not specifically presented with hip-related symptoms or instability. Nevertheless, this study allowed the evaluation of the full range of anatomical anomalies of the Down syndrome hip. Furthermore, only the osseous predisposition to instability was evaluated in this study but not how this predisposition would correlate to clinically discernable instability. This study evaluated the hip anatomy of patients with DS while in standing position. This position is not routinely used in clinical practice and surgical planning is typically performed based on radiographs taken while patient is supine. However, this technique allowed the evaluation of the hip anatomy of these patients in a functionally-relevant position, which is required for activities of daily living. Furthermore, this technique allowed the three-dimensional reconstruction of the pelvis and lower limbs and therefore a more thorough analysis of the Down syndrome hip anatomy (in particular in the axial plane) as well as allowing the calculation of anatomical equivalents of acetabular orientation parameters. Furthermore, certain parameters measured in this study could not have been otherwise evaluated using two-dimensional standard radiography such as the percentage of three-dimensional coverage of the femoral head by the acetabulum and the anterior and posterior acetabular sector angles. However, since the threshold values used in this study were derived from studies where radiographs were acquired in the supine position (Tannast et al., 2015; Tönnis, 1984; Tönnis and Heinecke, 1999) then their applicability to the current study may be limited by the difference in positioning. But the distributions of the Down syndrome patients according to these thresholds, regardless of their absolute values, served to reflect the heterogeneity of the Down syndrome hip which would still be found to be heterogeneous regardless of the absolute values of the thresholds used. Furthermore, this study did not involve an assessment of the kinematics of the hip joint (such as during gait) and the current data do not allow the authors to extrapolate to how these may be affected by the currently described alterations. Moreover, another limitation of this study is that a reproducibility study had not been performed on a subset of the included patients. However, the methodology used in this study (subject positioning, image acquisition, software used, operator performing the three-dimensional reconstructions) had been previously validated (Assi et al., 2013; Ghostine et al., 2016) and the bias and reproducibility values of those studies had been reported above in this study. It is notable that the same research team had previously performed these validation studies and that therefore the bias and reproducibility values could be considered applicable to the current study.

In conclusion, this is the first study of the three-dimensional hip anatomy of subjects with Down syndrome in the standing position. Subjects with Down syndrome were found to have similar global coverage of the femoral head by the acetabulum compared to controls but were found to have significantly more heterogeneous hip anatomy. While the hips of subjects with Down syndrome were found to be mostly anatomically predisposed to posterior instability, a significant proportion of hips were found to be predisposed to anterior instability. These findings emphasize that the anatomy of the hips of subjects with Down syndrome is highly heterogeneous and that their hips can be anatomically predisposed to both anterior and posterior instability. The surgeon should therefore bear in mind this heterogeneity when assessing such patients and consider the possibility of both anterior and posterior instability. Future interventional studies should determine whether three-dimensional imaging of the hips of subjects with Down syndrome complaining of instability could better refine surgical treatment strategies based on subject-specific three-dimensional hip anatomy.

\section{Conflict of interest}

None.

\section{Authorship}

Ziad Bakouny (1,2), Ayman Assi (1,2), Fares Yared (1), Nour Khalil (1), Elie Mansour (1), Jean Jacques Yaacoub (1), Wafa Skalli $(1,2,3)$, Ismat Ghanem $(1,2,3)$.

(1) the conception and design of the study, or acquisition of data, or analysis and interpretation of data, (2) drafting the article or revising it critically for important intellectual content, (3) final approval of the 
version to be submitted.

\section{Acknowledgment}

This research was funded by the University of Saint-Joseph (grant\# FM183). The authors did not receive any external funding for this study.

\section{References}

Abousamra, O., Bayhan, I.A., Rogers, K.J., Miller, F., 2016. Hip instability in down syndrome: a focus on acetabular retroversion. J. Pediatr. Orthop. 36, 499-504. https:// doi.org/10.1097/BPO.0000000000000484.

Aprin, H., Zink, W.P., Hall, J.E., 1985. Management of dislocation of the hip in down syndrome. J. Pediatr. Orthop. 5, 428-431. https://doi.org/10.1097/01241398198507000-00007.

Assi, A., Chaibi, Y., Presedo, A., Dubousset, J., Ghanem, I., Skalli, W., 2013. Three-dimensional reconstructions for asymptomatic and cerebral palsy children's lower limbs using a biplanar X-ray system: a feasibility study. Eur. J. Radiol. 82, 2359-2364. https://doi.org/10.1016/j.ejrad.2013.07.006.

Assi, A., Bakouny, Z., Mansour, E., Yaacoub, J.-J., Yared, F., Ghanem, I., 2018. Spinopelvic alignment in subjects with down syndrome. Clin. Spine Surg. https://doi. org/10.1097/BSD.0000000000000655.

Babisch, J.W., Layher, F., Amiot, L.-P., 2008. The rationale for tilt-adjusted acetabular cup navigation. J. Bone Joint Surg. Am. 90, 357-365. https://doi.org/10.2106/JBJS.F. 00628.

Bendaya, S., Lazennec, J.-Y., Anglin, C., Allena, R., Sellam, N., Thoumie, P., Skalli, W., 2015. Healthy vs. osteoarthritic hips: a comparison of hip, pelvis and femoral parameters and relationships using the EOS $^{\oplus}$ system. Clin. Biomech. 30, 195-204. https:// doi.org/10.1016/j.clinbiomech.2014.11.010.

Bennet, G.C., Rang, M., Roye, D.P., Aprin, H., 1982. Dislocation of the hip in trisomy 21. J. Bone Joint Surg. (Br.) 64, 289-294.

Boylan, M.R., Kapadia, B.H., Issa, K., Perfetti, D.C., Maheshwari, A.V., Mont, M.A., 2015. Down syndrome increases the risk of short-term complications after total hip arthroplasty. J. Arthroplast. 31, 1-5. https://doi.org/10.1016/j.arth.2015.09.031.

Diamond, L.S., Lynne, D., Sigman, B., 1981. Orthopedic disorders in patients with Down's syndrome. Orthop. Clin. North Am. 12, 57-71.

Dorr, L.D., Malik, A., Dastane, M., Wan, Z., 2009. Combined anteversion technique for total hip arthroplasty. Clin. Orthop. Relat. Res. 467, 119-127. https://doi.org/10. 1007/s11999-008-0598-4.

Gaumétou, E., Quijano, S., Ilharreborde, B., Presedo, A., Thoreux, P., Mazda, K., Skalli, W., 2014. EOS analysis of lower extremity segmental torsion in children and young adults. Orthop. Traumatol. Surg. Res. 100, 147-151. https://doi.org/10.1016/j.otsr. 2013.09.010.

Ghostine, B., Sauret, C., Assi, A., Bakouny, Z., Khalil, N., Skalli, W., Ghanem, I., Ghostine, B., Sauret, C., Assi, A., Bakouny, Z., Khalil, N., Skalli, W., G., I., 2016. Influence of patient axial malpositioning on the trueness and precision of pelvic parameters obtained from 3D reconstructions based on biplanar radiographs. Eur. Radiol. 27, 1295-1302. https://doi.org/10.1007/s00330-016-4452-X.

Hingsammer, A.M., Bixby, S., Zurakowski, D., Yen, Y.M., Kim, Y.J., 2015. How do acetabular version and femoral head coverage change with skeletal maturity? Clin. Orthop. Relat. Res. 473, 1224-1233. https://doi.org/10.1007/s11999-014-4014-y.

Horton, W.C., Brown, C.W., Bridwell, K.H., Glassman, S.D., Suk, S.-I., Cha, C.W., 2005. Is there an optimal patient stance for obtaining a lateral 36" radiograph? A critical comparison of three techniques. Spine (Phila Pa 1976) 30, 427-433. https://doi.org/ 10.1097/01.brs.0000153698.94091.f8.

Hresko, T.M., McCarthy, J.C., Goldberg, M.J., 1993. Hip disease in adults with Down syndrome. J. Bone Jt. Surg. 75, 604-607.

Janssen, M.M. a, Drevelle, X., Humbert, L., Skalli, W., Castelein, R.M., 2009. Differences in male and female spino-pelvic alignment in asymptomatic young adults: a three- dimensional analysis using upright low-dose digital biplanar X-rays. Spine (Phila Pa 1976) 34, E826-E832. https://doi.org/10.1097/BRS.0b013e3181a9fd85.

Kelley, S.P., Wedge, J.H., 2013. Management of hip instability in trisomy 21. J. Pediatr. Orthop. 33, 33-38. https://doi.org/10.1097/BPO.0b013e318281968e.

Knight, D.M. a, Alves, C., Wedge, J.H., 2011. Femoral varus derotation osteotomy for the treatment of habitual subluxation and dislocation of the pediatric hip in trisomy 21: a 10-year experience. J. Pediatr. Orthop. 31, 638-643. https://doi.org/10.1097/BPO. 0b013e3182285fa5.

Kumar, M.A., Shetty, M.S., Kiran, K.G., Kini, A.R., 2012. Validation of navigation assisted cup placement in total hip arthroplasty. Int. Orthop. 36, 17-22. https://doi.org/10. 1007/s00264-011-1268-9.

Lazennec, J.-Y., Brusson, A., Rousseau, M.-A., 2011. Hip-spine relations and sagittal balance clinical consequences. Eur. Spine J. 20, 1-13. https://doi.org/10.1007/ s00586-011-1937-9.

Lembeck, B., Mueller, O., Reize, P., Wuelker, N., 2005. Pelvic tilt makes acetabular cup navigation inaccurate. Acta Orthop. 76, 517-523. https://doi.org/10.1080/ 17453670510041501.

Mansour, E., Yaacoub, J.J., Bakouny, Z., Assi, A., Ghanem, I., 2017. A podoscopic and descriptive study of foot deformities in patients with Down syndrome. Rev. Chir. Orthop. Traumatol. 103. https://doi.org/10.1016/j.rcot.2016.11.003.

Melhem, E., Assi, A., El Rachkidi, R., Ghanem, I., 2016. EOS ${ }^{\oplus}$ biplanar X-ray imaging: concept, developments, benefits, and limitations. J. Child. Orthop. 10. https://doi org/10.1007/s11832-016-0713-0.

Mik, G., Gholve, P. a, Scher, D.M., Widmann, R.F., Green, D.W., 2008. Down syndrome: orthopedic issues. Curr. Opin. Pediatr. 20, 30-36. https://doi.org/10.1097/MOP. ob013e3282f35f19.

Quijano, S., Serrurier, A., Aubert, B., Laporte, S., Thoreux, P., Skalli, W., 2013. Threedimensional reconstruction of the lower limb from biplanar calibrated radiographs. Med. Eng. Phys. 35, 1703-1712. https://doi.org/10.1016/j.medengphy.2013.07. 002 .

Rousseau, M.-A., Lazennec, J.-Y., Boyer, P., Mora, N., Gorin, M., Catonné, Y., 2009. Optimization of total hip arthroplasty implantation. is the anterior pelvic plane concept valid? J. Arthroplast. 24, 22-26. https://doi.org/10.1016/j.arth.2007.12. 015 .

Sankar, W.N., Millis, M.B., Kim, Y.-J., 2011. Instability of the hip in patients with down syndrome. J. Bone Jt. Surg. 93, 1924. https://doi.org/10.2106/JBJS.J.01806.

Sankar, W.N., Schoenecker, J.G., Mayfield, M.E., Kim, Y.-J., Millis, M.B., 2012. Acetabular retroversion in down syndrome. J. Pediatr. Orthop. 32, 277-28 10.1097/BPO.0b013e31824b27fc.

Shaw, E., Beals, R., 1992. The hip joint in Down's Syndrome. A study of its structure and associated disease. Clin. Orthop. Relat. Res. 278, 101-107.

Tannast, M., Hanke, M.S., Zheng, G., Steppacher, S.D., Siebenrock, K.A., 2015. What are the radiographic reference values for acetabular under- and overcoverage? Clin. Orthop. Relat. Res. 473, 1234-1246. https://doi.org/10.1007/s11999-014-4038-3.

Tönnis, D., 1984. Die angeborene Hüftdysplasie und Hüftluxation im Kindes- und Erwachsenenalter: Grundlagen, Diagnostik, konservative und operative Behandlung. Springer. ed., Heidelberg, Germany.

Tönnis, D., Heinecke, a, 1999. Acetabular and femoral anteversion: relationship with osteoarthritis of the hip. J. Bone Joint Surg. Am. 81, 1747-1770. https://doi.org/10. 2106/JBJS.L.00710.

Vialle, R., Levassor, N., Rillardon, L., Templier, A., Skalli, W., Guigui, P., 2005. Radiographic analysis of the sagittal alignment and balance of the spine in asymptomatic subjects. J. Bone Joint Surg. Am. 87, 260-267. https://doi.org/10.2106/ JBJS.D.02043,

Woolf, S.K., Gross, R.H., 2003. Posterior acetabular wall deficiency in Down syndrome. J. Pediatr. Orthop. 23, 708-713. https://doi.org/10.1097/01241398-20031100000005.

Zeng, Y., Wang, Y., Zhu, Z., Tang, T., Dai, K., Qiu, S., 2012. Differences in acetabular morphology related to side and sex in a Chinese population. J. Anat. 220, 256-262. https://doi.org/10.1111/j.1469-7580.2011.01471.x.

Zywiel, M.G., Clohisy, J.C., Backstein, D., Gross, a E., 2013. Surgical Challenges and Clinical Outcomes of Total Hip Replacement in Patients with Down's Syndrome. vol. 95. pp. 41-45. https://doi.org/10.1302/0301-620X.95B11.32901. 